\author{
Asian Journal of \\ Medical and Biological Research \\ ISSN 2411-4472 (Print) 2412-5571 (Online) \\ www.ebupress.com/journal/ajmbr
}

\title{
Article \\ Assessment of job satisfaction among the senior staff nurses working at Sadar Hospital, Naogaon, Bangladesh
}

\author{
Hamima Umme Morsheda ${ }^{1}$, Md. Nahid Uz Zaman ${ }^{2 *}$ and Nahid Afroze ${ }^{3}$ \\ ${ }^{1}$ Nursing Instructor In-charge, Nursing Institute, Naogaon-6500, Bangladesh \\ ${ }^{2}$ Nursing Instructor, Dr. Jubeida Khatoon Nursing Institute, Rajshahi-6000, Bangladesh \\ ${ }^{3}$ Senior Staff Nurse, Bangabandhu Sheikh Mujib Medical University, Dhaka, Bangladesh \\ *Corresponding author: Md. Nahid Uz Zaman, Nursing Instructor, Dr. Jubeida Khatoon Nursing Institute, \\ Rajshahi-6000, Bangladesh. E-mail: nuz1192@gmail.com
}

Received: 21 November 2016/Accepted: 05 December 2016/ Published: 29 December 2016

\begin{abstract}
This study aimed to examine nurses' job satisfaction at Sadar Hospital, Naogaon, Bangladesh. It also examines the relationships between nurses' assessment, satisfaction, attitude, and practice with respect to job satisfaction. The descriptive cross sectional study design was used to explore the job satisfaction among the staff nurses. Total number of nurses working in this hospital was 121. A total number of fifty nurses were recruited into this study in order to overcome non-response subjects. The age group 30-39 years were 40\%, 40-49 years were $46 \%$ and $50+$ above were $14 \%$ nurses. Male nurses were only $6 \%$ and the female were $94 \%$. Marital status single $12 \%$, married $80 \%$, widow $8 \%$. Muslim nurses were $58 \%$, Hindu $38 \%$ and Christian $4 \%$. Academic qualification of them was SSC 66\% and H.S.C 34\%. Professional qualification was Diploma in Nursing /Diploma in Midwifery 92\%, B.Sc. in public Health Nursing 6\% and MPH 2\%. Length of service 1 to 10 years $22 \%, 11$ to 20 years $50 \%, 21$ to 25 years $24 \%, 31+$ years $4 \%$. Regarding maintaining therapeutic relationship; facing problem in duty; keeping records; receiving complicated patient; attend in duty time; maintaining aseptic techniques; maintaining work; carryout admission and discharge the results for all above questions were 100\% yes. But regarding satisfy to give care $30 \%$ respondent were not satisfied; whole for job salary $68 \%$ nurses were not feel enough and remaining $32 \%$ were satisfied. Again in case of promotion to the next post most of the respondent $16 \%$ were satisfied and $84 \%$ were not satisfied.
\end{abstract}

Keywords: assessment; job satisfaction; senior staff nurse; Sadar Hospital; Naogaon

\section{Introduction}

Job satisfaction is a complex and subjective phenomenon, according to the adopted theoretical framework, definition varies different authors conceptualized it as a pleasant emotional state, resulting from multiple aspect of work. It can be influenced by individuals 'aspiration, sadness, and joy thus affecting their attitude towards themselves, family and organization. Job satisfaction is determined by a comparison of one's prior expectations about the job and the actual experience of the job. It has been found that job satisfaction relates to beliefs and emotions that individuals have about their work and their job (Cranny et al., 1992). Job satisfaction may not pay enough or offers the benefits one needs. It may not utilize a person's skill or challenge creative side of one's talent (Needleman, 2007). The matching personal need the perceived potential of the occupation of satisfying those needs (Kallestal, 2004); related theory Maslow's Human needs theory.

Job satisfaction most commonly influence productivity, performance, absenteeism, turnover health and wellbeing. Therefore, it has turned into a source of organizational concern, and also in health, which present, on the hand, satisfaction with the relief of other people's suffering and on the other, dissatisfaction with the work overload and its precarious condition, leading to physical and mental exhaustion, low self-esteem and loss of interest in client/person comfort, triggering behaviours that range from attentiveness to joy, speed and efficiency 
to irritability, disinterest, bad mood and indelicacy. In order to have a successful organization being a higher authority should always ensure the employees' satisfaction level.

Nursing is a demanding profession. Nurses are bombarded daily with many tasks and responsibilities. Nursing today is practiced in various settings and is a vital part of the health care system. Nurses are present in hospitals, schools, rehabilitation centres, nursing homes, out-patient centres, clinics, and homes. A consumer perceives these professionals as trained individuals that work to contribute to a patient's maintenance and health issues. The school of nursing in Mauritius perceives the health care sector to have growing challenges (Marylene and Edward, 2005).

Job satisfaction is generally regarded as an employee's attitude toward the job and job situation. Spector (1997) defines job satisfaction simply as "the degree to which people like their jobs." Some people therefore enjoy work and consider it a central part of their lives while others do so only because they have to. At the same time one has to consider that the degree towards which different persons are satisfied concerning varies from country to country because different countries have got different types of work condition. Moreover people expectations have a myriad of differences in different countries (Spector, 1997).

Nurses in Bangladesh assess, provide preventative, curative and rehabilitative care for the sick and disabled in a wide variety of settings including public hospitals and private clinics, the community services, and in industry. In Bangladesh the regulating body for nurses is called Bangladesh Nursing Council (BNC). Although nursing has a long history of an ethic of care, the context in which nurses now practice has changed and expanded. Consequently, this has led to the establishment of the Code of Practice as nursing started orientating itself toward professionalism (Ordinance LXI 1983).

The aim of the present study was to find out the determinants of job satisfaction of nurses. The purpose was also to find out about the experiences of nurses in their hospital environment and to accumulate knowledge on the role of nurses. Also the criteria were that the nurses should have been educated and at the same time have a minimum of 2 years of experience in nursing field. According to nurses at Sadar Hospital, Naogaon where this study was carried out, no previous researches have been done investigating about job satisfaction among nurses in that hospital.

\section{Materials and Methods}

The descriptive cross sectional study was used to assess of job satisfaction among the senior staff nurses working at Sadar Hospital, Naogaon, Bangladesh. The study was conducted at Sadar Hospital, Naogaon, a 250 beded secondary level hospital, which is located in Naogaon city of Bangladesh. Approximately 80 patients per day are admitted in this hospital. The study was carried out from January 2016 to June 2016. Total number of nurses working in this hospital was 121 . Fifty nurses interviewed questionnaire with a response rate of $100 \%$.

\section{Results}

\subsection{Demographic information on participating nurses}

At the demographic information Table 1, the age group 30-39 years were 40\%, 40-49 years were $46 \%$ and 50+ above were $14 \%$ nurses. Male nurses were only $6 \%$ and the female were $94 \%$. Marital status single $12 \%$, married $80 \%$, widow $8 \%$. Muslim nurses were 58\%, Hindu $38 \%$ and Christian $4 \%$. Academic qualification of them was SSC 66\% and H.S.C 34\%. Professional qualification was Diploma in Nursing /Diploma in Midwifery 92\%, B.Sc. in public Health Nursing 6\% and MPH 2\%. Length of service 1 to 10 years 22\%, 11 to 20 years $50 \%, 21$ to 25 years $24 \%, 31+$ years $4 \%$.

\subsection{Job related question to the nurse}

Regarding maintaining therapeutic relationship, facing problem in duty, Keeping records, receiving complicated patient, attend in duty time, maintaining aseptic techniques, maintaining work, carryout admission and discharge the results for all (100\%) above questions was yes. But regarding satisfy to give care $30 \%$ respondent was not satisfied; whole for job salary $68 \%$ nurses was not feel enough and remaining $32 \%$ were satisfied. Again in case of promotion to the next post most of the respondent $84 \%$ nurses were satisfied.

\subsection{Factors related to job satisfaction}

At the nurses knowledge questionnaire Table 3, there selected questions are job related factors- personal factors $18 \%$, money $60 \%$, wish to help $22 \%$; Feelings towards job -successful $60 \%$, wish to help $16 \%$, choice to job shift $26 \%$. Experience as a nurse in this work place- Fulfil the desire to help the patient $26 \%$, demanding but rewarding $74 \%$. 
Table 1. Demographic information of the participated nurses.

\begin{tabular}{llll}
\hline Variable & Parameters & No. & Percentage \\
\hline \multirow{3}{*}{ Age } & $30-39$ year & 20 & 40 \\
& $40-49$ year & 23 & 46 \\
\multirow{2}{*}{ Gender } & 50-59 year & 7 & 14 \\
\hline \multirow{3}{*}{ Marital status } & Male & 3 & 6 \\
& Female & 47 & 94 \\
\hline \multirow{5}{*}{ Religion } & Single & 6 & 12 \\
& Married & 40 & 80 \\
& Widow & 4 & 8 \\
\hline \multirow{3}{*}{ Academic qualification } & Muslim & 29 & 58 \\
& Hindu & 19 & 38 \\
& Christian & 2 & 4 \\
\multirow{3}{*}{ Professional qualification } & Buddhist & 0 & 0 \\
\hline \multirow{5}{*}{ Length of service } & S. S. C. & 33 & 66 \\
& H. S. S. & 17 & 34 \\
& B. Sc. /B.A & 0 & 0 \\
\hline & Diploma in Nursing and Midwifery & 46 & 92 \\
& B. Sc. in Nursing & 3 & 6 \\
& MPH / M. Sc. & 1 & 2 \\
\hline
\end{tabular}

Table 2. Information on knowledge of the participated nurses regarding job.

\begin{tabular}{|c|c|c|c|c|c|}
\hline \multirow{3}{*}{ No. } & \multirow{3}{*}{ Question } & \multicolumn{4}{|c|}{ Answer } \\
\hline & & \multicolumn{2}{|c|}{ Yes } & \multicolumn{2}{|c|}{ No } \\
\hline & & No. & $\%$ & No. & $\%$ \\
\hline 1 & $\begin{array}{l}\text { Do you establish and maintain therapeutic relationship with the } \\
\text { patient? }\end{array}$ & 50 & 100 & 0 & 0 \\
\hline 2 & Have you inform about personal hygiene to the patient? & 87 & 87 & 13 & 13 \\
\hline 3 & Have you face any problem in your duty time? & 50 & 100 & 0 & 0 \\
\hline 4 & Do you keep and maintain all records related to the patient? & 50 & 100 & 0 & 0 \\
\hline 5 & Have you received complicated patient cordially? & 50 & 100 & 0 & 0 \\
\hline 6 & Do you attend duty in time? & 50 & 100 & 0 & 0 \\
\hline 7 & Do you maintain your work properly in hospital regularly? & 50 & 100 & 0 & 0 \\
\hline 8 & $\begin{array}{l}\text { Do you carry out admission and discharge procedures with proper } \\
\text { formalities? }\end{array}$ & 50 & 100 & 0 & 0 \\
\hline 9 & $\begin{array}{l}\text { Do you check the case sheet routinely in each shift with necessary } \\
\text { measures? }\end{array}$ & 50 & 100 & 0 & 0 \\
\hline 10 & Do you manage any problem in emergency situation? & 50 & 100 & 0 & 0 \\
\hline 11 & Do you ensure proper reporting and record keeping? & 50 & 100 & 0 & 0 \\
\hline 12 & Do you encourage to the patient to maintain regular records? & 79 & 79 & 21 & 21 \\
\hline 13 & Do you satisfy in giving proper care? & 15 & 30 & 35 & 70 \\
\hline 14 & Do you satisfy in your promotion? & 8 & 16 & 42 & 84 \\
\hline 15 & Have you any problem to maintain the rules in nursing job? & 20 & 40 & 30 & 60 \\
\hline 16 & Do you maintain in your shifting duty? & 50 & 100 & 0 & 0 \\
\hline 17 & Do you satisfy in your salary? & 34 & 68 & 16 & 32 \\
\hline
\end{tabular}


Table 3. Factors related to job satisfaction.

\begin{tabular}{lllll}
\hline Q. No & Variable & Parameters & No. & \% \\
\hline \multirow{2}{*}{ 1. } & Explain the job related factors that & Personal factor & 9 & 18 \\
& influence your job satisfaction. & Money & 30 & 60 \\
& & Wish to help & 11 & 22 \\
\hline \multirow{2}{*}{2.} & & Successful & 30 & 60 \\
& \multirow{2}{*}{ Explain your feelings towards this job. } & Wish to help & 8 & 16 \\
& & Choice of job shift & 13 & 26 \\
\hline \multirow{2}{*}{3.} & Please write about your experience as a & Fulfil the desire to help the patient & 13 & 26 \\
& nurse in this ward place & Demanding but rewarding & 37 & 74 \\
\hline
\end{tabular}

\section{Discussion}

Research has suggested that nurse satisfaction is positively correlated with patient satisfaction (Teresa, 1996). This correlation is important because it is commonly accepted that satisfied patients return to healthcare facilities for their future medical needs which leads to increased profits from the return business. Patient satisfaction has always been important in nursing, but recently even more emphasis has been put on this area.

The link between high employee job satisfaction and patient satisfaction may be a result of several different things. One possibility is that nurses increase productivity when they are satisfied. Another is that there are fewer turnovers of registered nurses (RNs) when they are satisfied with their jobs. A lower turnover rate means that there is less potential for nurses to be working understaffed and the nurses are more experienced in the facility in which they are working. This is important because when nurses are understaffed they are not able to give each patient the time and attention that they deserve. Studies have shown that understaffing has led to negative outcomes for patients (Bellandi, 2001; Morrissey, 2002).

Research has also found that patients are more likely to have positive outcomes in facilities with higher ratios of nurses who have baccalaureate or higher degrees (Aiken et al., 2002). These positive outcomes are likely to lead to higher patient satisfaction and therefore higher nurse satisfaction.

This present study provided information that is important to nursing administration, practice, and education. Administrators could use this information to build solid and supportive units. This is important to because the culture of the unit and the quality of nursing staff affects every aspect of a nurse's practice and also the patients' care. Finally, this study is important to education because it can be used as a building block to assist in developing and researching strategies to attract and also retain nurses. Also, when there is poor retention in a facility, the educations of nurses suffer due to the lack of experienced nurses to mentor new nurses.

\section{Conclusions}

The factors which influenced their job satisfaction seemed to be more politically and managerial oriented for example not all the nurses were happy with the work place. Salary was often mentioned the open ended question concerning the job related factors that affected them. All of them were satisfied with their salary. Culturally it also showed that money is an important factor in job satisfaction and job dissatisfaction in Bangladesh and it depended if the work as a nurse was a primary or secondary job in a family. In general most of the nurses seem to be satisfied or quite satisfied with their work, which shows that only a minority were not happy with this field and are still working. The quality of care is not same as in Europe but still the quality of care is at an acceptable level in the Bangladesh point of view. At the moment the results from this study provides updated information about job satisfaction of nurses and how nurses in feel about their work place, work atmosphere and employer. This study provided information that is important to nursing administration, nursing practice, and nursing education. It was found that the nurses in this sample were moderately satisfied with their jobs. The results also revealed that motivation and hygiene factors had strong, positive, and almost equal correlations with overall satisfaction.

\section{Acknowledgement}

We would like to express our deep appreciation with gratitude to my respected authority of Sadar Hospital, Naogaon and the participated nurses who willingly took part in the data collection procedure.

\section{Conflict of interest}

None of declare. 


\section{References}

Aiken LH, J Buchan, Sochalskl and Powell, 2002. Trends in international nurse migration. Health Affairs, 23:69-77.

Bellandi D, 2001. Labor flexes muscle: United American Nurses votes to join AFL-CIO sends message to bosses. Modern Healthcare, 8:23-34.

Cranny CJ, P Smith and E Stone, 1992. Job satisfaction. How People Feel About Their Jobs and How It Affects Their Performance. USA. McMillan.

Kallestal, 2004. Organizational behavior (2nd ed.). Boston: Allyn and Bacon, Inc.

Marylene G and L Edward, 2005. The relationships between job enrichment, job satisfaction and service quality: An exploratory study in the retail industry in South Africa. Management Dynamics, 12:2-12.

Morrissey J. 2002. Nurses are necessary. Modern Healthcare, 32(32), 20. Retrieved October 14, 2002, from Proquest database.

Needleman J, 2007. Job satisfaction among South African aircraft pilots [Electronic version]. SA Journal of Industrial Psychology, 29: 52-57.

Ordinance LXI, 1983. The Motivation Handbook. London: CIPD.

Spector P, 1997. Job satisfaction: Application, assessment, causes and consequences. Sage publications Inc.

Teresa M, 1996. A task level assessment of job satisfaction. Journal of Organizational Behavior, 16: 101-121. 